It is thus seen that about 4 per cent. of patients carried upon the hospital registers are at home on parole.

Desiring to obtain definite information of the workings of this system in this State, I recently wrote the superintendent of each of the large public hospitals for the insane inquiring as follows:-

1. How many patients have you on your register?

2. How many are at home on parole?

3. Is any supervision exercised over patients out on parole?

4. Is any special effort made to get harmless chronic cases out on parole?

5. Do you approve the system?

To these questions the various superintendents courteously replied as follows:-

Dr. Arthur Loewy, of the Northern, reports 1,115 patients on the register, with 30 at home on parole. Paroled patients are supervised by correspondence with their friends. He always recommends the removal of harmless chronic cases whenever they can be cared for at home. He approves the parole system.

Dr. W. C. Lence, of the Southern, states that at his institution no supervision of paroled patients is exercised, except to instruct the friends to return them if they become worse. Special efforts are made to get patients out on parole, and he approves the system.

Dr.J. F. McKenzie, of the Central, says: "We exercise no supervision over patients on parole. They simpiy have the privilege of returning within the quarter without further legal proceedings. We are compelled to make considerable effort to get chronic cases sent bome in order to make room for acute ones, as our institution is now, and has been for several years, full to overflowing. I think the system of granting parole is a good one."

Dr. Ciarke Gapen, of the Eastern. says: "There is no special supervision exercised over patients who are out on pa. role, except when we send a special attendant to accompany them, which we do at times. There has been no special effort made to get harmless chronic cases out on parole. I think, however, that much could be done, not only to relieve the institutions, but for the benefit of the patients themselves by such efforts. . . . There are many patients in this Institution who, I think, could get on outside.

the friends or county authorities could be induced to take a proper interest in them. . . In answer to your fifth ques. tion. I would say that I do approve of the parole system, as it is difficult for us to say positively when discharging a patient whether such patient is in condition to bear the strain of ordinary life or not, and this can generally only be ascertained by trial. The quasi-criminal method of commitment in vogue in Itlinois, makes it a very unpleasant thing for a half-recovered patient to be re-committed to an institution."

Dr. MeGr'w, of the Cook County Insane Asylum, says:"We have 1.067 insane patients on the register. Very few are at home on parole. . . . No special supervision by the asylum authorities is exercised over patients after they leave the institution. Friends are required to assume all responsibility after patients are removed. . . No special effort is made to get harmless chronic cases at home on parole; neither is any great objection made to friends removing them if they desire, because of the over crowded condition of the wards. We believe that the insane, including the harmless chronic cases can be better cared for-with more advantage to themselves by the asylum system rather than at home."

The advantages of the parole system, as practiced, over the boarding-out system lie in the fact that the harmless chronic insane are in the hands of their relatives and friends, who are apt to take in them a more kindly interest than would strangers who were actuated solely by mercenary motives. The subject is one of interest and practical importance and well worthy of extended inquiry and caref ul consideration. (To be continued.)

Blank Applications for membership in the Associatros at the Journal office.

\section{THE TREATMENT OF EXTENSIVE BURNS.}

Read before the Chicago Pathologlcal Society, Sept. 10, 1894.

\section{BY EMANUEL FRIEND, M.D.}

CHICAGO.

Of all accidents which befall the human race none, in my opinion, call for more speedy and at the same time scientific treatment to alleviate pain, shock and subsequent infection than an extensive burn of the second or third degree, may it be caused by the mere flame, molten metals, boiling fats, hot water, steam and the like. It is not the object of this paper to go into the minutiæ of etiology, symptomatology or pathologic anatomic changes characterizing the different forms and degrees of burns, but merely to hint at the anatomic changes taking place in the three gradations under which all burns are classified, and suggest a method of application of one of the oldest and best of therapeutic measures, namely water.

In burns of the first degree, dermatitis combustionis erythematosa, we get a mild hyperemia of the papillary vessels of the corium with consecutive paresis and passive congestion, which causes a slight swelling and redness. If an exudation takes place, and such is generally the case to a greater or less extent, a yellowish discoloration takes place; whether this is caused by the instantaneous application of a flame or by the heat of the sun, as in erythema solore, the changes are practically the same.

Burns of the second degree, dermatitis combustionis bullosa, are characterized by the appearance of bullæ, and vesicles of various sizes from a pin head to the size of the palm of one's hand, and even larger, which are due to a serous exudation from the papillary and upper vessels of the corium separating in part or the entire thickness of the epidermis from the corium beneath. Generally, one sees innumerable blebs and bullæ, which have ruptured from, no doubt, sudden over-distension from the rapid accumulation of serum and corpuscular elements; and also in consequence of the trauma, from the patient's hands, in his endeavor to extinguish the flame, we have great shreds of epidermis hanging from the corium.

Microscopically, the appearance is the same, whether the bullæ or vesicles be caused by steam, fire or a vesicant. Through the kindness of $\mathrm{my}$ frieud, Docent Riehl, of Vienna, in presenting me with a piece of tissue containing a vesicle, caused by a mustard plaster just previous to the death of the patient, I am enabled to give the following brief analysis of the same:

The tissue after fixation and hardening was stained with lithium carmine and picric acid, Zeiss ocular No. 3, obj. a. On either side of the field one sees the remains of the epidermis which has been lifted from the corium beneath, in this specimen having been ruptured in the center, possibly in process of preparation; still adherent to the under and outer surface one sees epidermoidal elements, indicating that just at this point separation had taken place in the stratum lucidum, while beneath and still adherent to the corium one sees intact rete malphigii with several layers of prickle cells. The center of the epidermoidal covering of this bullæ, or rather vesicle is lost, but the corium with its obliterated papillæ indicates that a complete separation of the rete malphigii and overlaying layers of epidermis had taken 
place here. The contiguous papillæ are widened, the $\mid$ beds, and a nurse in constant attendance. Through vessels dilated, while the connective tissue fibers are the kindness of Professor Kaposi and his first assistswollen and literally teased asunder by the exudate ant, Dr. Lukasiewicz, now Professor of Dermatology of serum, with its corpuscular elements; the latter in the University of Zürich, Switzerland, I was enahaving taken the lithium carmine stain quite bled to study these cases, by having access to this markedly.

water bed ward at any and all times. Of all appli-

Burns of the third degree, dermatitis combustionis ances and devices invented by man to relieve human escharotica. In this degree the elements of the suffering, I know of none which is entitled to greater corium have suffered primarily from the continuous credit than the Hebra water bed in the treatment of application of the heat, causing a mortification. burns. It is practically an oblong tank seventy-eight According to the agent producing the same, the parts inches long, twenty-eight and one-half inches wide, become charred, bronzed, or dried and leathery. Fre- twenty-one inches deep, lined with zinc, shown in the quently one sees in the bronzed denuded surface, accompanying plan designated (Fig. $1 \mathrm{a}$ ). Supporting twig-like figures representing the coagulated and car- this tank are two head posts three by two inches and bonized contents of the superficial vessels. The em- forty-nine inches in height, and two at the foot meas-

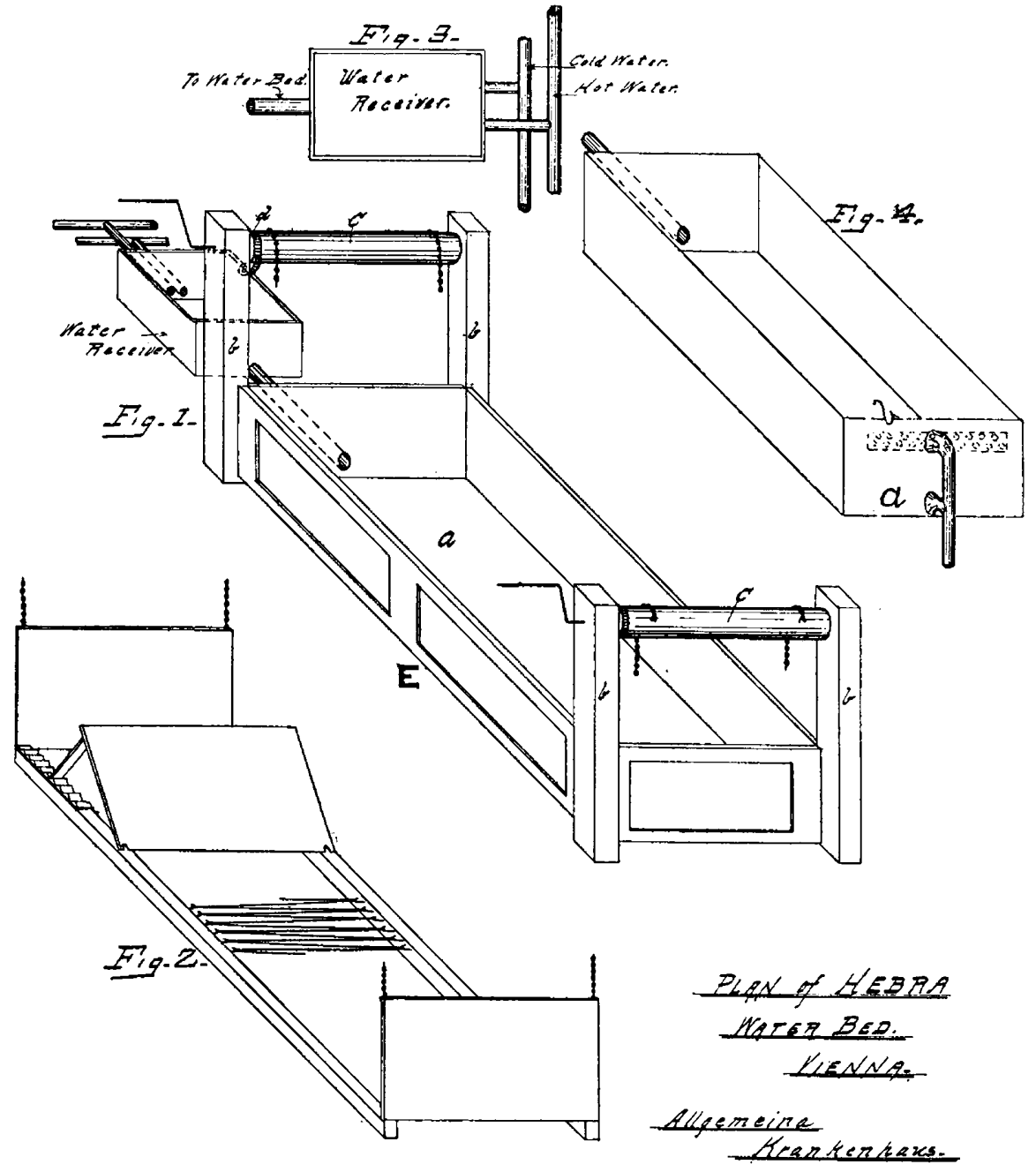

inent medico-legal authority, E. Hofman, of Vienna, uring the same. (Fig. $1 b$ ). Between both the two head has shown that this injection of the vessels does not become apparent when the body of a murdered person is subsequently burnt, and also that the deeper tissues are afforded a considerable protection by the superficial layers of the epidermis and corium. Thus has been shown in the cremation of bodies to what a great heat, continuously applied, the tissues must be subjected before an effect is perceptible on the deeper tissues.

In Vienna, all cases of severe burning are taken to posts and the two foot posts, is a windlass, (Fig. $1 \mathrm{c}$ ), both of which can be turned by means of a crank which is adjustable. At each end of the cylinder of the windlass is a chain, used to support an oblong steel framework or mattress (Fig. 2) which fits snugly to the inside of the tank, when lowered by means of the windlass. Along the sides of this mattress are placed hooks opposite one another, across which are strung wires (the same as the springs of our bed the dermatologic wards of the Wiener Are the support a blanket, which is thrown Kre or rather Krankenhaus, and cared for in a room set apart from within about eighteen inches of the head of this matthe general wards, provided with seven Hebra water tress is attached an upright, serving as a pillow sup- 
port (Fig. $2 a$ ) which can he raised or lowered to suit the patient's convenience, it being supported by a $\operatorname{cog}$ and rachet arrangement, which is also found attached to the head windlass of the bed proper (Fig $1 d)$.

At the head of the tank (Fig. $1 a$ ), but separate and distinct from same, is a water receiver (Fig. 3 ) connected to the tank by a single pipe; merging into this receiver is both a cold and hot water pipe, coming either from a range or boiler, according to the source of the hot water. The temperature of the water is hence regulated here instead of at the main tank. Naturally, the large tank (Fig. $1 a$ ) is supplied with an escape pipe and a safety escape to prevent an overflow. (Fig. $4 a, b$.)

Fig. $1 \mathrm{E}$ represents the side woodwork of the bed.

Upon the patient's arrival, orders are given the nurse to prepare the water bed, whose arrangement as you have seen is so simple that an inexperienced hand can prepare it in five minutes. The tempera. ture of the water should be about 25 or 26 degrees $R$., and increased after the immersion to 32 or 34 degrees $\mathrm{R}$.

The patient is carefully lifted onto to the blanket covering the mattress, which is swung above the water's surface, which should reach to almost onethird of the top edge of the tank. Almost at the instant the patient is immersed his heartrending shrieks and moans will subside, and if asked after five minutes, regarding his condition, will state that he now feels comfortable. If necessary, stimulants can be given and if the patient be laboring under intense shock, the water can be made somewhat warmer than that which would give the most comfortable feeling to the patient, being gauged by the hand and thermometer. To the face is generally applied a mask of linen, saturated in carron oil. Within an hour or two, after the more acute symp. toms have subsided, the patient is raised out of the water, catheterized, and the loose shreds of epidermis trimmed off and existing bullæ are tapped, care being taken not to remove the epidermial covering. Then the case is treated symptomatically.

As I have before stated, the object of these few lines is not so much the recommendation of the agent (as water has been used from time immemorial for the treatment of burns by both the laity and physi cians) as it is the method of application, and consequently I would suggest the adoption of the water bed in all hospitals; possibly some ingenious mem. ber of the profession could suggest a plan by which the idea could be carried out in private practice, namely an apparatus adjustable to any bath tub.

I am certain that, had we been possessed of such th an apparatus during my term of service at the Michae! Reese Hospital, it would have been decidedly to the patients' advantage as well as our own.

The advantages claimed for the water bed are:

1. Relieving the patient almost instantly of the excruciating pain consequent on a severe burn, and following the application and removal of dressinge afterward.

z. Producing more rapid cicatrization.

3. Relieving shock.

4. Preventing infection from erysipelas, pus microorganisms, etc.

5. Prevention of amyloid degenerations due to the confinement of secretions by dressings.

6. Saving of expense of material and time in frequent dressing.
Patients may be allowed to follow this aquatic life for months and months, Kaposi reporting one patient having spent 385 consecutive days and nights in the water bed. They eat, drink, sleep and frequently gain considerably in weight in the bed. Not alone can burns be treated in this manner, but all forms of discase in which there is an extensive loss of epidermis as in pemphigus foliaceus, gangrene, or in chronic suppurating wounds.

\section{FACIAL BLEMISHES ; A PLEA FOR THE STUDY OF THE SCIENCE AND ART OF COSMETICS.}

BY EDWARD H. SCHAEFER, M.D., Ph.L.

KANSAS CITY, MO.

There are many affections and defects of the body that demand the attention of the physician, who, in applying his knowledge of how to relieve and accomplish a cure, thinks he has done all that he is able to do.

There is still one branch left, belonging to the external part of the human frame, to which very little attention has been devoted and even arbitrarily excluded from the province of medicine, and that is the science of cosmetics. Physicians have always searched for hidden troubles of the human economy, diseases that are internal, not discernible by the eye, thereby entirely ignoring the outward conditions of man.

That branch of medicine, intimately connected with dermatology, the science and art of cosmetics, has been until recently a kind of terra incognita, being exclusively in the hands of empyrics or nonprofessional persons. For ages, men, and women especially, have striven to enhance their personal attractiveness, augmenting beauty and symmetry to their forms. What remedial means and agents could be utilized in order to beautify face and body were the source of greatest speculation. Every one, man and woman, wishes to appear attractive, which naturally is as it should be, and all means that are employed in that direction to accomplish the desired end, are truly commendable. How often will a woman refuse to take medicine for some slight trouble, but can be persuaded with ease to do so, if she is reminded that some cosmetic blemishes might be the result. The impressions made upon us by persons depend largely upon their external appearance. Anything pleasing in its nature will be estimated in a favorable measure of opinion.

Our ideas relate more or less to esthetics, be it in the form of objects or persons. Women, knowing this perquisite to attractiveness have, since the remotest ages used all such remedies at their command that would heighten their bodily charms. We all are aware how concerned women often are about any eruption on the face, as for instance, acne, lenticular spots, chloasma and other facial blemishes too numerous to mention. Should this not in itself he a mild reminder of the necessity that the physician ought to concern himself more about those diseases of the skin that occur mostly upon the face and which often leave marks or imprints? How well could he apply his knowledge of the anatomy of the skin in making operations upon the face for tumors and other growths, so as to avoid leaving cicatrices. Young men and women may be seen walking along the streets, who have their faces literally disfigured 